\title{
Sex-Dependent Decrease of Sphingomyelinase Activity During Alcohol Withdrawal Treatment
}

\author{
Christiane Mühle Violina Amova $^{a}$ Teresa Biermanna Kristina Bayerlein ${ }^{a, d}$ \\ Tanja Richter-Schmidinger ${ }^{a}$ Thomas Kraus ${ }^{b}$ Martin Reichel ${ }^{a}$ Erich Gulbins ${ }^{c}$ \\ Johannes Kornhuber ${ }^{\mathrm{a}}$ \\ aDepartment of Psychiatry and Psychotherapy, Friedrich-Alexander-University of Erlangen-Nuremberg, \\ ${ }^{b}$ Frankenalb Clinic for Psychiatry, Psychotherapy, Psychosomatic Medicine and Rehabilitation from \\ Addiction, Engelthal, 'Department of Molecular Biology, University of Duisburg-Essen, Essen, dpresent \\ address: Regional Hospital of Middle Frankonia, Department of Psychiatry, Addiction, Psychotherapy \\ and Psychosomatic Medicine, Erlangen, Germany
}

\section{Key Words}

Acid sphingomyelinase $\bullet$ Alcohol dependence $\bullet$ Craving $\bullet$ Depression $\bullet$ Gender $\bullet$ Psychometrics - Withdrawal

\begin{abstract}
Background: In vitro and in vivo studies have demonstrated the role of the acid sphingomyelinase (ASM) in pathophysiological processes and alterations in response to ethanol exposure. Cellular and plasmatic ASM activities are increased in male alcohol dependent patients and decrease during physical withdrawal. Methods: Here, we analyzed the time course of ASM in male and also female acutely intoxicated patients during alcohol withdrawal and compared the activity levels to those under long-term maintenance treatment. Craving and further psychometric parameters were assessed by questionnaires. Results: The gradual decrease of serum ASM was confirmed in males $(p<0.001)$ and continued to lower activities in long-term patients $(p=0.001)$. The trend was similar in females $(p=0.178)$, although the initial enzyme activities were significantly lower $(p=0.035)$. ASM activity strongly correlated with the body mass index in males. The initial ASM activity and its decline during the first two days were associated with the improvement in scores for the Beck depression inventory, the obsessive compulsive drinking and the withdrawal syndrome scales. Conclusion: These data support the potential of ASM as a biomarker for the course of withdrawal therapy in males and provide the first associations of this enzyme with psychological variables such as craving and depression.
\end{abstract}


Mühle et al.: Secretory Sphingomyelinase During Alcohol Withdrawal Treatment

\section{Introduction}

The harmful use of alcohol is associated with a variety of physiological changes and neuropsychiatric symptoms that considerably impact individual quality of life, mortality, and detrimentally affect society. In view of the high prevalence of alcohol use disorders and the increase in the frequency of hazardous and harmful drinking patterns (e.g., intoxication among adolescents and young adults $[1,2])$, there is an urgent need for improvement of preventive and therapeutic actions.

Changes in the lipid metabolism have been implicated in a variety of diseases including those associated with acute or chronic alcohol consumption [3]. The enzymes of the sphingolipid metabolism play a crucial role in maintaining the balance between bioactive lipids (e.g., the proapoptotic ceramide and the anti-apoptotic sphingosine-1-phosphate, known as the "rheostat" [4,5]), and thereby control diverse cellular processes including proliferation, differentiation, growth arrest and apoptosis [6]. Among these enzymes, the glycoprotein acid sphingomyelinase (ASM, EC 3.1.4.12) catalyzes the hydrolysis of the major eukaryotic membrane constituent sphingomyelin to yield phosphorylcholine and ceramide which can be further degraded to sphingosine. A lysosomal form of the enzyme (L-ASM) is widely distributed in mammalian tissues [7] and is encoded by the same gene SMPD1 as a $\mathrm{Zn}^{2+}$-dependent secretory isoform (S-ASM) [8] that can be found in human plasma and serum.

A number of in vitro and in vivo animal studies have suggested an influence of ethanol on the sphingomyelinase/ceramide system. A dose-dependent activation of neutral sphingomyelinase and a decrease in sphingomyelin content was observed in liver cells [9]. Ethanol treatment of astrocytes was associated with the stimulation of neutral and acid sphingomyelinase, ceramide generation and the subsequent activation of signaling pathways implicated in cell death [10]. Both ceramide concentrations and apoptosis rate were decreased by simultaneous addition of the functional ASM inhibitor desipramine [10]. Ethanol-induced ceramide accumulation was also observed in primary rat neurons, human and mouse neuroblastoma cells [11]. In a murine model of alcohol-enhanced lipopolysaccharide hepatotoxicity, ASM activity was increased and associated with an elevated ceramide content in tissues [12]. Another ASM inhibitor, imipramine, blocked the ethanol-induced ASM activation and ceramide generation and resulted in amelioration of hepatic steatosis in ethanol-fed mice [13]. A comparison of ASM(+/+) with ASM(-/-) mice has revealed that ASM is required for chronic alcohol induced hepatic endoplasmatic reticulum stress, liver injury and sensitization to lipopolysaccharide [14].

There are, however, few human studies relating ASM and alcoholism. Liver biopsies from patients with alcoholic hepatitis exhibited 2-3-fold higher expression levels of ASM and endoplasmatic reticulum stress markers at the mRNA level than samples from control subjects [14]. We have previously observed an altered peripheral ASM activity in alcohol dependent patients: L-ASM levels were increased in acutely intoxicated individuals' blood mononuclear cells and decreased during withdrawal [15]. Similarly, the activity of plasmatic S-ASM dropped remarkably by about $50 \%$ from day 0 to day 10 of physical withdrawal to levels that were still above those of healthy controls [16]. In the search for peripheral biomarkers as surrogates for central physiological as well as psychological changes, the activity of S-ASM would thus be a promising candidate. However, these data were obtained only in male patients that constitute the majority of alcohol addicts, and no psychological data were assessed from this group.

In this report, we confirm the previously observed decrease of S-ASM activity in male patients during alcohol withdrawal therapy and extend these results to females that show a slightly different pattern. Furthermore we provide the first data for associations of S-ASM activities with psychometric variables. 
Mühle et al.: Secretory Sphingomyelinase During Alcohol Withdrawal Treatment

Table 1. Characteristics of the study sample. BMI: body mass index. Statistical tests for significance (t-test, Welch test and Wilcoxon-Mann-Whitney test) were applied as appropriate, $\mathrm{p}<0.05$ in bold. Values are given as mean \pm standard deviation

\begin{tabular}{|c|c|c|c|c|c|c|c|c|}
\hline & \multicolumn{2}{|c|}{ male } & \multicolumn{2}{|c|}{ female } & \multicolumn{2}{|c|}{$\mathrm{p}$ (male vs. female) } & \multicolumn{2}{|c|}{$\mathrm{p}$ (acute vs. long-term } \\
\hline & acute & long-term & acute & long-term & acute & long-term & male & female \\
\hline number of patients & 16 & 23 & 13 & 4 & & & & \\
\hline age (years) & $50.0 \pm 11.5$ & $42.5 \pm 9.1$ & $48.7 \pm 9.8$ & $36.8 \pm 8.1$ & 0.749 & 0.246 & 0.029 & 0.047 \\
\hline BMI $\left(\mathrm{kg} / \mathrm{m}^{2}\right)$ & $25.8 \pm 4.1$ & $26.2 \pm 3.6$ & $25.9 \pm 4.1$ & $20.5 \pm 3.0$ & 0.954 & 0.006 & 0.750 & 0.031 \\
\hline alcohol consumption (years of drinking) & $26.8 \pm 12.8$ & $19.9 \pm 11.8$ & $17.0 \pm 10.4$ & $11.5 \pm 9.8$ & 0.039 & 0.190 & 0.090 & 0.367 \\
\hline alcohol consumption (total g/day) & $330 \pm 277$ & $371 \pm 139$ & $176 \pm 72$ & $318 \pm 235$ & 0.049 & 0.540 & 0.559 & 0.316 \\
\hline time since last detoxification (days) & $878 \pm 2135$ & $103 \pm 147$ & $539 \pm 675$ & $65.0 \pm 25.6$ & 0.617 & 0.974 & 0.359 & 0.042 \\
\hline number of detoxification treatments & $5.4 \pm 12.8$ & $1.9 \pm 2.1$ & $6.2 \pm 6.1$ & $2.3 \pm 1.3$ & 0.032 & 0.272 & 0.836 & 0.236 \\
\hline S-ASM activity on day $0(\mathrm{fmol} / \mathrm{h} / \mu \mathrm{l})$ & $773 \pm 233$ & - & $579 \pm 238$ & - & 0.035 & - & - & - \\
\hline S-ASM activity on day $2(\mathrm{fmol} / \mathrm{h} / \mathrm{\mu l})$ & $602 \pm 227$ & - & $490 \pm 180$ & - & 0.162 & - & - & - \\
\hline S-ASM activity on day $7(\mathrm{fmol} / \mathrm{h} / \mathrm{\mu l})$ & $548 \pm 166$ & - & $462 \pm 154$ & - & 0.159 & - & - & - \\
\hline S-ASM activity long-term $(\mathrm{fmol} / \mathrm{h} / \mathrm{\mu l})$ & - & $372 \pm 112$ & - & $426 \pm 144$ & - & 0.396 & - & - \\
\hline S-ASM change from day 0 to day $2(\mathrm{fmol} / \mathrm{h} / \mu \mathrm{l})$ & $-172 \pm 119$ & - & $-89 \pm 193$ & - & 0.166 & - & - & - \\
\hline S-ASM change from day 0 to day $7(\mathrm{fmol} / \mathrm{h} / \mathrm{\mu l})$ & $-225 \pm 194$ & - & $-118 \pm 204$ & - & 0.158 & - & - & - \\
\hline
\end{tabular}

\section{Materials and Methods}

\section{Patient recruitment}

Patients were recruited as part of the Franconian Alcoholism Research Study (FARS-IV) at the University of Erlangen-Nuremberg during the years 2009/2010 according to the protocol established in previous studies [17]. They had not previously taken part in this group of studies. Recruitment took place at two locations: the Department of Psychiatry and Psychotherapy of the University Hospital Erlangen ( $n=14)$ and the Frankenalb Clinic for Psychiatry, Psychotherapy and Psychosomatic Medicine in Engelthal $(n=42)$. The study was approved by the local ethics committee under number 3926. All participants gave informed written consent in accordance with the Declaration of Helsinki after thorough explanation of the study and were diagnosed with alcohol dependence according to the Diagnostic and Statistical Manual of Mental Disorders (Fourth Edition) and the International Classification of Diseases (Tenth Revision). Subjects were between 24 and 74 years of age, of Caucasian-white ethnicity, and seen either as inpatients for detoxification treatment during the first 7 days ("acute", $\mathrm{n}=29$ ) or during their inpatient dehabituation therapy ("longterm", $\mathrm{n}=27$, Table 1). Study characteristics (Table 1 ) including medical history were obtained using a semistructured interview. The patient cohort is considered representative since nearly all patients who were asked for participation without prior selection and who had not started withdrawal therapy yet agreed to take part in the study. Patients' total alcohol consumption was calculated from the self-reported consumed volume of beer $(40 \mathrm{~g} / \mathrm{L})$, wine $(80 \mathrm{~g} / \mathrm{L})$ and spirits $(300 \mathrm{~g} / \mathrm{L})$. Blood was collected into ethylene diamine tetraacetate or serum vials (Sarstedt), respectively, from nonfasting patients at the day of admission ("day 0 "), during early abstinence (on "day 2") and at the end of physical withdrawal at day 7-10 ("day 7") between 8 and 10 a.m. or during the morning from nonfasting patients on the maintenance program. Samples were centrifuged within two hours and plasma/serum aliquots were stored at $-80^{\circ} \mathrm{C}$ until further use.

\section{Psychometric assessment}

On each study day, participants additionally took several psychometric questionnaires. The Withdrawal Syndrome Scale for Alcohol and Related Psychoactive Drugs (WSA, [18]) comprises a set of typical withdrawal symptoms subdivided into somatic symptoms (pulse rate, blood pressure, temperature, breathing rate, sweating and tremor) and mental symptoms (agitation, contact, orientation, hallucinations and anxiety). Alcohol craving was measured using the Obsessive Compulsive Drinking Scale (OCDS) as a well-validated and reliable 14-item self-rating instrument that provides two subscale scores for a number of cognitive aspects of alcohol craving [19, 20], and the Lübecker Craving Survey (LCF, [21]) with six questions. Moreover a visual analogue scale for alcohol craving (VAS) was applied where patients indicate their current level of craving by a mark along a line connecting two anchor statements: strong vs. no craving. The degree of physical dependence to smoking tobacco was measured by the Fagerström Test for Nicotine Dependence (FTND) and comprised of six questions [22-24]. The Beck Depression Inventory (BDI, [25, 26]), a 21-question multiple-choice self-report inventory, was applied to assess the severity of depression. The Global Assessment of Functioning scale (GAF, [27, 28]) - a scale that integrates three different dimensions of functioning including psychological, social and occupational - was used to rate the patient's severity of 
psychiatric illness. Finally, acute and long-term patients answered the 5 items of the Satisfaction with Live Scale (SLWL, $[29,30])$ using a 1-7 Likert scale.

\section{Enzyme activity assay}

The activity of S-ASM in serum and plasma was determined using the fluorescent substrate BODIPYFL-C12-sphingomyelin (N-(4,4-difluoro-5,7-dimethyl-4-bora-3a,4a-diaza-s-indacene-3-dodecanoyl) sphingosyl phosphocholine, D-7711, Invitrogen) with three replicates each as previously described [31]. Briefly, the reaction containing $116 \mathrm{pmol}$ substrate in a total volume of $100 \mu \mathrm{l} 200 \mathrm{mM}$ sodium acetate buffer (pH 5.0) with $500 \mathrm{mM} \mathrm{NaCl}, 0.2 \%$ Nonidet P-40 detergent and $500 \mu \mathrm{M} \mathrm{ZnCl}_{2}$ was initiated by the addition of a $1.5 \mu \mathrm{l}$ sample. After incubation for $24 \mathrm{~h}$ at $37^{\circ} \mathrm{C}$, reactions were halted by freezing the mix at $-20^{\circ} \mathrm{C}$; the reactions were then stored until further processing. Next, lipids were extracted with $250 \mu \mathrm{l}$ chloroform:methanol $(2: 1, \mathrm{v} / \mathrm{v})$. The lower organic phase was then concentrated in a SpeedVac centrifuge (Christ Alpha 1-4), dissolved in $2 \mu \mathrm{l}$ chloroform:methanol (2:1, v/v) and spotted on silica gel 60 thin layer chromatography plates (Macherey-Nagel, 805034). Ceramide and uncleaved sphingomyelin were separated using a mixture of chloroform:methanol $(80: 20, \mathrm{v} / \mathrm{v})$ as a solvent and were quantified on a Typhoon Trio scanner (GE Healthcare; $488 \mathrm{~nm}$ excitation, $520 \mathrm{~nm}$ emission, $285 \mathrm{~V}, 100 \mu \mathrm{m}$ resolution) with the QuantityOne software (Bio-Rad Laboratories). Enzymatic activity is presented as the hydrolysis rate of sphingomyelin (fmol) per time $(\mathrm{h})$ and per sample volume $(\mu \mathrm{l})$.

\section{Conversion of plasma to serum S-ASM activities}

Corresponding plasma and serum samples were available for a subset of patients and were analyzed in parallel to determine whether enzyme activities of S-ASM are equivalent. There was a strong correlation between plasma and serum activities $\left(r=0.763\right.$, $\mathrm{p}($ Spearman $\left.)=1.2 \times 10^{-13}, \mathrm{n}=70\right)$ indicating that both sample types can be used for this assay. Since serum samples were more complete and are often preferentially collected in studies for the applicability in enzyme linked immunosorbent assays, we chose the serum activities for further analyses. For four patients, S-ASM values were calculated from plasma activities according to the obtained linear regression curve (serum-activity $=1.095 \times$ plasma-activity + $30.9 \mathrm{fmol} / \mathrm{h} / \mu \mathrm{l}$ ) due to missing serum samples.

\section{Statistical analysis}

Statistical analysis was conducted using IBM SPSS Statistics Version 21.0. Analysis included a general linear model, ANOVA for repeated measurements, Student's t-test, Welch test, Wilcoxon-Mann-Whitney test, and Pearson and Spearman correlations (all two-tailed) as appropriate, with a significance level of 0.05. Deviation from the normal distribution and homoscedasticity were checked using the Kolmogorov-Smirnov test and Levene's test, respectively. Values in the text, tables and figures represent the mean \pm standard deviation and nominal $\mathrm{p}$ values that are uncorrected with respect to multiple testing.

\section{Results and Discussion}

\section{Demographics of the study group}

Male and female patients were recruited from two hospitals and from two settings: acute withdrawal versus long-term dehabituation therapy. All groups showed similar characteristics (Table 1). Importantly, acute male and female patients were of similar age and body mass index (BMI). Significant sex-specific differences were present for the number of detoxification treatments, the duration and the amount of alcohol consumption for acute patients and the BMI for long-term patients. These demographic data correspond well to the known higher typical drinking quantities, frequencies and rates of heavy drinking episodes in men compared to women across cultures [32]. Long-term patients were of younger age compared to the acute group; female long-term patients also differed in BMI and the time since last detoxification.

\section{Sex-specific time course of S-ASM activity during withdrawal therapy}

Samples from patients during detoxification treatment were analyzed for S-ASM activity at the day of admission, at day 2 and at the end of physical withdrawal at day 7-10. These 


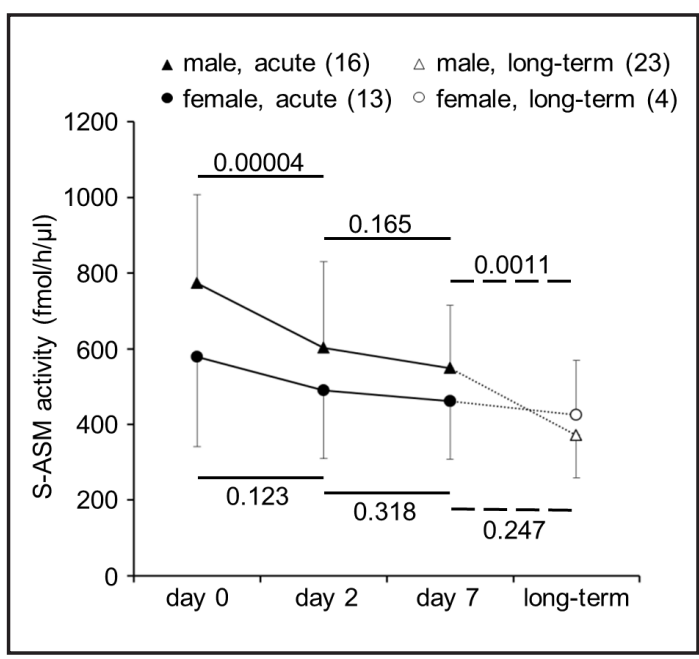

Fig. 1. S-ASM activity decreased during detoxification treatment from day 0 , day 2 and day 7 (same patients assessed at different time periods, paired ttest) from initially increased levels particularly high in males. Values are compared to different patients in maintenance therapy (unpaired t-test). Mean values with the standard deviations as error bars are shown.

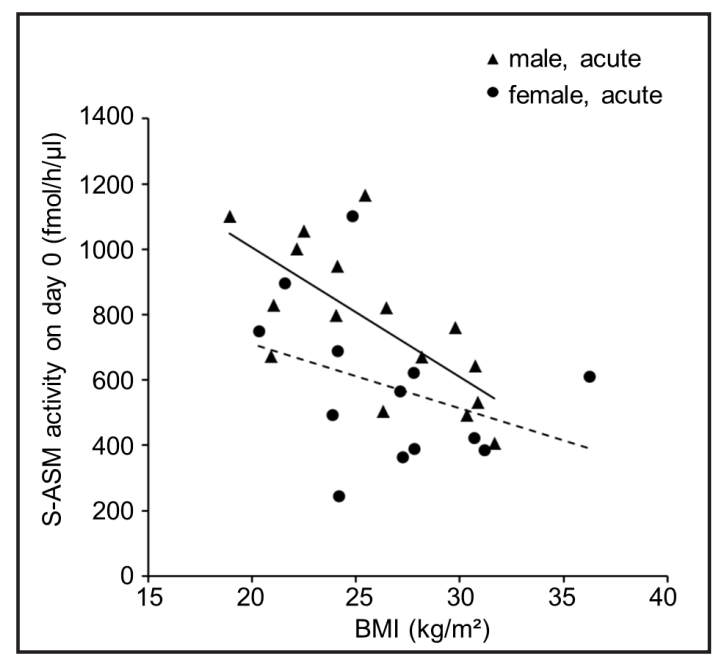

Fig. 2. Association between BMI and S-ASM activity in males (continuous line) and in females (dashed line).

results were compared to sober patients within a dehabituation program. In agreement with published plasma data [16], the serum S-ASM activity decreased significantly during withdrawal therapy in males $(F=16.239, p=0.0002)$ by an average of $27 \%$ of the initial value and was even lower in long-term patients (Fig. 1). Compared to males, the initial serum S-ASM activity in female patients was significantly lower $(\mathrm{p}=0.035$, Table 1$)$ and thus, during withdrawal, the decrease by $15 \%$ in total of the initial value was not significant $(\mathrm{F}=2.030$, $p=0.178$ ). For both sexes, most of the enzyme activity decrease took place during the first two days, with a three-fold higher relative standard deviation of the day 0 to day 2 changes for females $(217 \%)$ compared to males ( $69 \%, p=0.104$, see Table 1 for absolute values).

It is interesting to note that enzymatic activities not only start at higher levels in alcohol dependent males, but also appear to decrease to lower levels during long-term maintenance therapy compared to females (Fig. 1). While this difference of $13 \%$ in long-term patients is not significant $(\mathrm{p}=0.396)$, it conforms to our data from healthy young adults: around $7 \%$ higher S-ASM activity was also observed in 102 females compared to 54 males ( $\mathrm{p}(\mathrm{t}-$ test $)=0.218$, unpublished results). The gender difference in initial S-ASM activities on day 0 may be explained by the significantly different amount of total alcohol consumed in absolute terms (330 $\pm 277 \mathrm{~g}$ in males vs. $176 \pm 72 \mathrm{~g}$ in females) as well as with respect to the duration of alcohol drinking ( $26.8 \pm 12.8$ years vs. $17.0 \pm 10.4$ years, respectively, Table 1$)$. However, both parameters did not significantly correlate with any S-ASM activity in both sexes (total alcohol: $r=-0.224, p=0.405$ for males and $r=-0.128, p=0.691$ for females; duration: $r=-0.066, p=0.807$ for males and $r=0.130, p=0.686$ for females for S-ASM on day 0 ).

We have thus replicated our previous data for alcohol-dependent males [16] in an independent group of male patients. The presence of an increased S-ASM activity in alcohol addicts compared to healthy individuals of both sexes was moreover supported by a further decrease of enzyme activities after the end of physical withdrawal at day 7-10 of acute patient to levels in long-term patients. In addition to this confirmation, we have observed a similar trend - albeit with some remarkable different aspects - for female patients during withdrawal therapy that deserve further attention in a larger sample. Such studies should preferably include different age groups to analyze the interaction with hormonal changes 
Table 2. Association of S-ASM activity with changes in psychometric scales (correlation coefficients $r$ with $\mathrm{p}$ value in brackets from Pearson or Spearman correlation analysis, as appropriate; $\mathrm{p}<0.05$ in bold)

\begin{tabular}{llcccccc}
\hline & & S-ASM on & all & & \multicolumn{2}{c}{ male } & \multicolumn{2}{c}{ female } \\
& day 0 & S-ASM & S-ASM on \\
change day & day 0 & $\begin{array}{c}\text { S-ASM } \\
\text { change day } \\
0 \text { to 2 }\end{array}$ & $\begin{array}{c}\text { S-ASM on } \\
\text { day 0 }\end{array}$ & $\begin{array}{c}\text { S-ASM } \\
\text { change day } \\
0 \text { to 2 }\end{array}$ \\
\hline Change & Obsessive Compulsive & $\mathbf{- 0 . 5 2 7}$ & $\mathbf{0 . 4 4 4}$ & $\mathbf{- 0 . 5 7 5}$ & 0.345 & -0.490 & 0.554 \\
in score & Drinking Scale (OCDS) & $\mathbf{( 0 . 0 0 7 )}$ & $\mathbf{( 0 . 0 2 6 )}$ & $\mathbf{( 0 . 0 3 1 )}$ & $(0.227)$ & $(0.126)$ & $(0.077)$ \\
from & Withdrawal Syndrome & -0.214 & $\mathbf{0 . 4 6 6}$ & -0.324 & $\mathbf{0 . 7 2 0}$ & -0.140 & 0.318 \\
day 0 & Scale (WSA) & $(0.316)$ & $\mathbf{( 0 . 0 2 2 )}$ & $(0.259)$ & $\mathbf{( 0 . 0 0 4 )}$ & $(0.701)$ & $(0.371)$ \\
to day 7 & Global Assessment of & 0.334 & 0.192 & 0.421 & 0.145 & 0.094 & $\mathbf{0 . 6 1 7}$ \\
& Functioning (GAF) & $(0.119)$ & $(0.380)$ & $(0.173)$ & $(0.653)$ & $(0.783)$ & $\mathbf{( 0 . 0 4 3 )}$ \\
& Beck Depression & -0.277 & $\mathbf{0 . 5 3 8}$ & -0.501 & 0.363 & -0.143 & $\mathbf{0 . 6 8 8}$ \\
& Inventory (BDI) & $(0.181)$ & $\mathbf{( 0 . 0 0 6 )}$ & $(0.068)$ & $(0.202)$ & $(0.676)$ & $\mathbf{( 0 . 0 1 9 )}$ \\
\hline Day 0 & Initial BDI score & 0.093 & -0.188 & $\mathbf{0 . 6 5 8}$ & $\mathbf{- 0 . 5 2 3}$ & -0.067 & -0.172 \\
& & $(0.645)$ & $(0.348)$ & $\mathbf{0 . 0 0 8}$ & $\mathbf{0 . 0 4 5 )}$ & $(0.837)$ & $(0.592)$ \\
\hline
\end{tabular}

during life-time. For example, elevated testosterone levels in female mice chronically exposed to ethanol, and less reduction of estrogen levels during withdrawal compared to male mice, suggest an important role of altered androgen signaling in the sexually dimorphic response to alcohol abuse [33].

The sphingomyelinase/ceramide system has been linked to the action of a variety of factors including reactive oxygen species and proinflammatory cytokines. In a recent report, Lee et al. have demonstrated that treatment of murine primary cerebral endothelial cells with homocysteine induces cell death by activating the ASM/ceramide pathway [34]. Interestingly, together with the observation of hyperhomocysteinaemia in chronic alcoholics and a steady decrease of homocysteine levels during alcohol withdrawal [17,35], this effect of homocysteine might possibly represent one factor leading to elevated S-ASM levels in alcohol dependent patients. However, supplementation of wild type mice with betaine to prevent hyperhomocysteinaemia did not abolish alcohol-stimulated ASM activation [14]. Although abundant and regulatable sources of S-ASM including macrophages and vascular endothelial cells have been identified [36], the origin of the increased S-ASM activity within the context of alcohol dependence remains elusive. Possible mechanisms range from transcriptional upregulation of ASM mRNA in endothelial cells to increased secretion [36], regulation at the level of splice variants [37] or altered proteolytic degradation as a response to factors such as oxidative stress.

\section{Correlation of S-ASM activity with BMI}

Analysis of the correlation between the BMI and S-ASM activity revealed a strong negative association only for male acute patients upon all three examinations (day $0: \mathrm{r}=-0.698$, $p=0.003$, day $2: r=-0.715, p=0.002$, day 7: $r=-0.579, p=0.019$, Fig. 2). This association was absent in male long-term patients $(\mathrm{p}=0.669)$. Although the indirect relationship with lower S-ASM activity for subjects with higher BMI was also present in females and was also strongest on day $2(r=-0.580, p=0.061)$, the correlation failed to become significant at any period.

Overall, these data fit well with the observed inverse correlation of plasmatic S-ASM activity with BMI in our previous group of male alcohol dependent patients [16]. Of note, in a different pathological condition, highest S-ASM activities were observed in cachectic versus non-cachectic patients suffering from chronic heart failure and S-ASM activity was also negatively correlated with BMI in these patients [38]. Interestingly, this inverse relationship between S-ASM activity and BMI seems to be connected to elevated S-ASM levels under pathological conditions and/or to higher age since we did not find this association in healthy young female $(r=0.007, p=0.948, n=98$, age $=24.3 \pm 3.3$ years $)$ and male $(r=0.086, p=0.561$, $\mathrm{n}=48$, age $=25.7 \pm 3.3$ years) adults (unpublished results). Similarly, no difference in serum sphingolipid concentrations was found between healthy lean and obese adolescents [39]. 
Inter-correlations of ASM activities

Since serum ASM activities in both sexes generally moved towards normal levels during withdrawal, an association between the enzyme activity on day 0 with the total decrease from day 0 to day 7 could be expected. The correlation was unexpectedly strong (Fig. 3A, $r=-0.758, p=2 \times 10^{-5}$ ) and was present in both sexes despite the lower overall decrease in females and despite the high variation of individual levels on day 0 and day 7 . With most of the change taking place during the first two days, the assumed association between the total activity change and the decrease from day 0 to day 2 was proven (Fig. 3B, $r=0.783$, $\left.\mathrm{p}=1 \times 10^{-5}\right)$. In a general linear model, both parameters - the initial activity and the change to day 2 - as covariates predict $75 \%$ (corrected $\mathrm{R}^{2}$ ) of the variability of the total change in S-ASM activity during withdrawal therapy.

\section{Association of S-ASM activity with psychometric data}

Of all total psychometric scale scores on the day of admission, only the BDI score for males was significantly associated with the S-ASM activity on the same day and with the change of S-ASM from day 0 to day 2; in contrast, there was not even a trend for females (Table 2, Fig. 3C, 3D). However, the initial ASM activity and the change of ASM activity from day 0 to day 2 proved as interesting indicators for the improvement in psychological variables. Among the eight assessed scales, changes of four scores from day 0 to day 7 were associated with ASM activities with p-values below 0.05 (Table 2, Fig. 3). For OCDS, WSA and BDI, high initial S-ASM activities and stronger changes from day 0 to day 2 were associated with stronger decreases in scores. That is, there was more improvement of the patients' psychological condition in terms of less craving and withdrawal symptoms and less depression. There was only a weak significant association in females for the S-ASM change and the improvement in the GAF score. No associations were observed for two other measurements of craving: the VAS with one single item only, and the LCF with six items. Neither nicotine dependence (FTND), nor satisfaction with life (SWLS) or their changes, were associated with ASM parameters. In general, based on similar trends of S-ASM activity changes during withdrawal in males and females, all correlations with improvement in psychological scale scores were in the same direction for both sexes.

Whereas reports on associations between ASM and craving or withdrawal symptoms are missing from the literature, several studies suggest a general connection between the enzyme's activity and depression. Firstly, we have previously observed a positive correlation between L-ASM activities in peripheral blood mononuclear cells of patients with a major depressive episode and their score on the clinician-administered Hamilton Depression Rating Scale [40]. Whether this effect translates to alcohol dependent patients with considerably lower self-rated depression scores and to S-ASM levels that are not highly correlated to L-ASM activities [16], or whether the result of the present study is an independent association of the ASM with depression requires more detailed investigation. Secondly, many commonly used antidepressant drugs such as amitriptyline and fluoxetine act as functional inhibitors of L-ASM in cell culture and mouse models [41-43]. The influence of a supplemental therapy with these drugs during alcohol withdrawal on S-/L-ASM activity and improvement in psychological variables could be analyzed in a pharmacological study. Finally, experiments in mouse models of stress-induced depression have demonstrated that the antidepressant effect of some drugs is mediated by their functional inhibition of L-ASM and consequently reduced levels of ceramide [43]. While this effect follows a delayed time course presumably required for the accumulation of the drug within lysosomes and for slow adaptive changes, it would be worthwhile to determine ceramide levels in the patients' serum samples and relate these to changes in ASM activities and scores. Although these would only represent peripheral markers, serum sphingomyelin and ceramide concentrations, for example, have been shown to serve as predictors of memory impairment in early Alzheimer's disease pathogenesis [44].

Despite the small group size of this study, we were able to replicate our previous data on S-ASM activities in males and to extend the observed decrease of the enzyme's activity to 


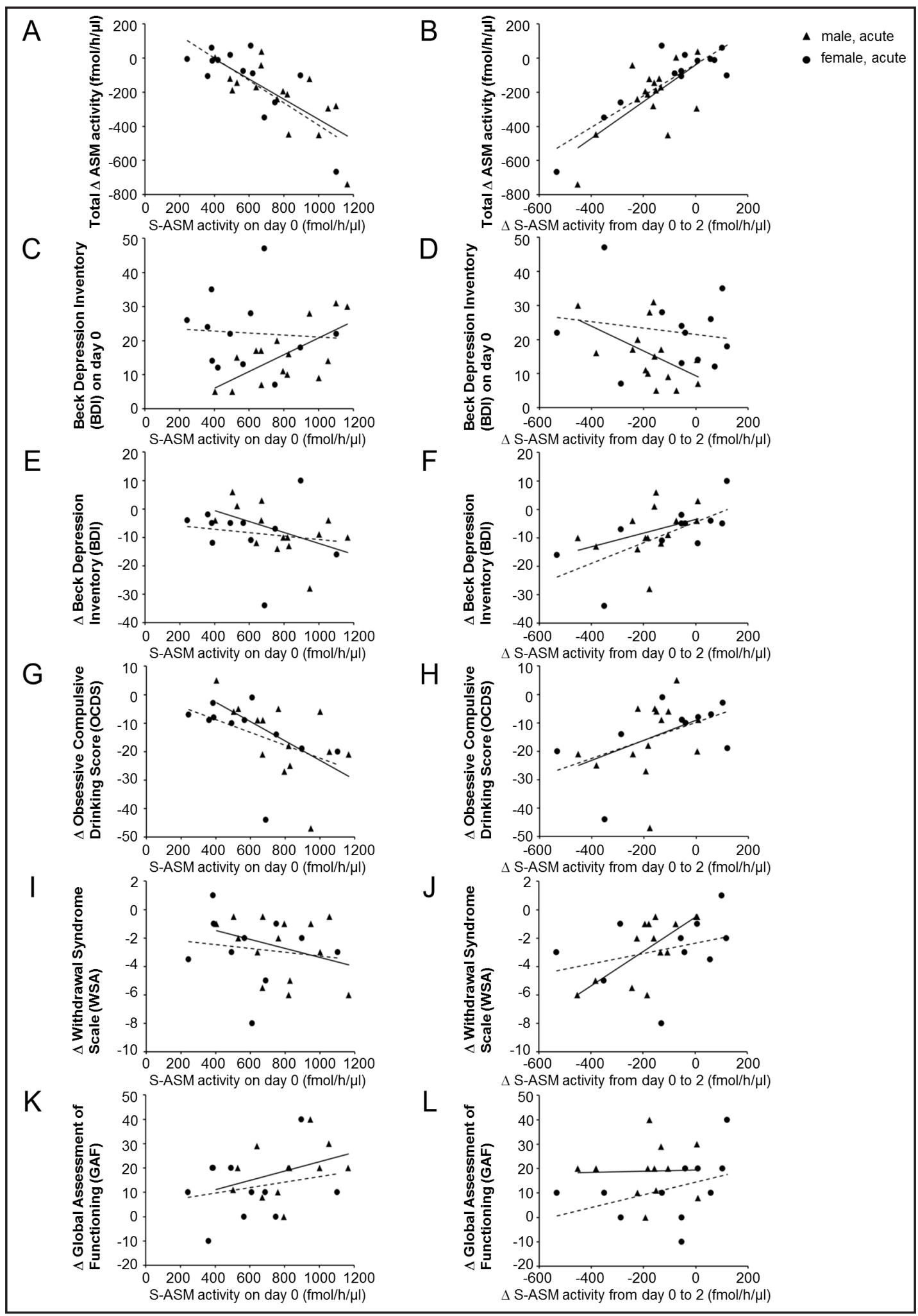

Fig. 3. Associations of the initial S-ASM activity on day 0 (left column) and the S-ASM activity change from day 0 to day 2 (right column) with the total ASM activity decrease (A, B), the initial BDI score on day 0 (C, D) and with total changes from day 0 to day 7 in scores for BDI (E, F), OCDS (G, H), WSA (I, J) and GAF (K, L) including linear regression lines for male (continuous line, triangles) and female (dashed line, circles) patients. 
female patients during alcohol withdrawal therapy. To verify the associations of psychometric scales with ASM activities detected in our pilot study, larger groups of females and males should be analyzed in more detail taking into account separate items and subscales for craving. Due to incomplete physiological data and blood parameters as well as scarce data on treatment strategies, these parameters could not be correlated with ASM activities or changes in psychological variables. However, it would be interesting to analyze the effect of, for example, the withdrawal medication, blood alcohol and homocysteine levels on S-ASM and psychometric scores.

In conclusion, the S-ASM activity in acute alcohol dependent male and female patients and patients undergoing withdrawal therapy might serve as a biomarker and could possibly present a potential additional target for intervention with respect to drug craving therapy and relapse prevention that deserves further investigation. In a pilot study, the sensitivity of S-ASM as a marker for problematic drinking in males was similar to that of carbohydratedeficient transferrin [16] - an established biomarker of chronic alcohol consumption particularly indicating high-risk drinking [45]. With the smaller increase in S-ASM activity levels in acutely intoxicated female patients, the utility of this enzyme as a biomarker for drinking in females might be limited and needs to be investigated in a larger sample. The kinetics of the change in S-ASM activity and its dependence on the frequency of alcohol intake (single event versus chronic) deserves further study. Moreover, the genetic influence of common polymorphisms on the S-ASM activity [46] must be taken into account.

\section{Disclosure Statement}

The authors declare that they have no conflict of interest.

\section{Acknowledgements}

We thank Irina Leinonen and Denise Pilniok for support in patient recruitment and sample collection. This work was supported by funding from the Deutsche Forschungsgemeinschaft grants GU 335/23-1 and KO 947/11-1 and from the Interdisciplinary Center for Clinical Research Erlangen, Project E13. We acknowledge support by the Deutsche Forschungsgemeinschaft and the Friedrich-Alexander-University of Erlangen-Nuremberg within the funding program Open Access Publishing.

\section{References}

1 World Health Organization: Global status report on alcohol and health 2011.

-2 Rehm J, Mathers C, Popova S, Thavorncharoensap M, Teerawattananon Y, Patra J: Global burden of disease and injury and economic cost attributable to alcohol use and alcohol-use disorders. Lancet 2009;373:22232233.

3 Baraona E, Lieber CS: Effects of ethanol on lipid metabolism. J Lipid Res 1979;20:289-315.

4 Hait NC, Oskeritzian CA, Paugh SW, Milstien S, Spiegel S: Sphingosine kinases, sphingosine 1-phosphate, apoptosis and diseases. Biochim Biophys Acta 2006;1758:2016-2026.

5 Spiegel S, Cuvillier O, Edsall LC, Kohama T, Menzeleev R, Olah Z, Olivera A, Pirianov G, Thomas DM, Tu Z, Van Brocklyn JR, Wang F: Sphingosine-1-phosphate in cell growth and cell death. Ann N Y Acad Sci 1998;845:11-18.

6 Hannun YA, Obeid LM: The ceramide-centric universe of lipid-mediated cell regulation: Stress encounters of the lipid kind. J Biol Chem 2002;277:25847-25850.

7 Weinreb NJ, Brady RO, Tappel AL: The lysosomal localization of sphingolipid hydrolases. Biochim Biophys Acta 1968;159:141-146. 


\section{Cellular Physiology $\quad$ Cell Physiol Biochem 2014;34:71-81 and Biochemistry

8 Schissel SL, Keesler GA, Schuchman EH, Williams KJ, Tabas I: The cellular trafficking and zinc dependence of secretory and lysosomal sphingomyelinase, two products of the acid sphingomyelinase gene. J Biol Chem 1998;273:18250-18259.

-9 Liu JJ, Wang JY, Hertervig E, Cheng Y, Nilsson A, Duan RD: Activation of neutral sphingomyelinase participates in ethanol-induced apoptosis in Hep G2 cells. Alcohol Alcohol 2000;35:569-573.

10 Pascual M, Valles SL, Renau-Piqueras J, Guerri C: Ceramide pathways modulate ethanol-induced cell death in astrocytes. J Neurochem 2003;87:1535-1545.

11 Saito M, Cooper TB, Vadasz C: Ethanol-induced changes in the content of triglycerides, ceramides, and glucosylceramides in cultured neurons. Alcohol Clin Exp Res 2005;29:1374-1383.

-12 Deaciuc IV, Nikolova-Karakashian M, Fortunato F, Lee EY, Hill DB, McClain CJ: Apoptosis and dysregulated ceramide metabolism in a murine model of alcohol-enhanced lipopolysaccharide hepatotoxicity. Alcohol Clin Exp Res 2000;24:1557-1565.

13 Liangpunsakul S, Rahmini Y, Ross RA, Zhao Z, Xu Y, Crabb DW: Imipramine blocks ethanol-induced asmase activation, ceramide generation, and pp2a activation, and ameliorates hepatic steatosis in ethanol-fed mice. Am J Physiol Gastrointest Liver Physiol 2012;302:G515-523.

14 Fernandez A, Matias N, Fucho R, Ribas V, Von Montfort C, Nuno N, Baulies A, Martinez L, Tarrats N, Mari M, Colell A, Morales A, Dubuquoy L, Mathurin P, Bataller R, Caballeria J, Elena M, Balsinde J, Kaplowitz N, Garcia-Ruiz C, Fernandez-Checa JC: ASMase is required for chronic alcohol induced hepatic endoplasmic reticulum stress and mitochondrial cholesterol loading. J Hepatol 2013;59:805-813.

15 Reichel M, Greiner E, Richter-Schmidinger T, Yedibela Ö, Tripal P, Jacobi A, Bleich S, Gulbins E, Kornhuber $\mathrm{J}$ : Increased acid sphingomyelinase activity in peripheral blood cells of acutely intoxicated patients with alcohol dependence. Alcohol Clin Exp Res 2010;34:46-50.

16 Reichel M, Beck J, Mühle C, Rotter A, Bleich S, Gulbins E, Kornhuber J: Activity of secretory sphingomyelinase is increased in plasma of alcohol-dependent patients. Alcohol Clin Exp Res 2011;35:1852-1859.

17 Bleich S, Carl M, Bayerlein K, Reulbach U, Biermann T, Hillemacher T, Bönsch D, Kornhuber J: Evidence of increased homocysteine levels in alcoholism: The franconian alcoholism research studies (FARS). Alcohol Clin Exp Res 2005;29:334-336.

18 Wetterling T, Kanitz RD, Besters B, Fischer D, Zerfass B, John U, Spranger H, Driessen M: A new rating scale for the assessment of the alcohol-withdrawal syndrome (AWS scale). Alcohol Alcohol 1997;32:753-760.

19 Anton RF, Moak DH, Latham PK: The obsessive compulsive drinking scale: A new method of assessing outcome in alcoholism treatment studies. Arch Gen Psychiatry 1996;53:225-231.

20 Mann K, Ackermann K: Die OCDS-G: Psychometrische Kennwerte der deutschen Version der Obsessive Compulsive Drinking Scale. Sucht 2000;46:90-100.

-21 Wetterling T, Veltrup C, Junghanns K: How to assess craving for alcohol. Eur Addict Res 1997;3:110-115.

-22 Fagerström KO: Measuring degree of physical dependence to tobacco smoking with reference to individualization of treatment. Addict Behav 1978;3:235-241.

-23 Heatherton TF, Kozlowski LT, Frecker RC, Fagerström KO: The Fagerström test for nicotine dependence: A revision of the Fagerström tolerance questionnaire. Br J Addict 1991;86:1119-1127.

24 Bleich S, Havemann-Reinecke U, Kornhuber J: Der Fagerström-Test für Nikotinabhängigkeit (FTNA). Beltz Test GmbH 2002; Göttingen.

25 Beck AT, Ward CH, Mendelson M, Mock J, Erbaugh J: An inventory for measuring depression. Arch Gen Psychiatry 1961;4:561-571.

26 Hautzinger M, Bailer M, H. W, Keller F: Beck-Depressions-Inventar (BDI). Testhandbuch Bern, Göttingen, Toronto, Seattle: Verlag Hans Huber 1994.

27 Hall RC: Global assessment of functioning. A modified scale. Psychosomatics 1995;36:267-275.

28 Saß H, Wittchen HU, Zaudig M, Houben I: Diagnostische Kriterien des diagnostischen und statistischen Manuals psychischer Störungen. DSM IV. Göttingen: Hogrefe 2003:47-49.

29 Diener E, Emmons RA, Larsen RJ, Griffin S: The satisfaction with life scale. J Pers Assess 1985;49:71-75.

30 Schumacher J, Klaiberg A, Brähler E: Diagnostische Verfahren zu Lebensqualität und Wohlbefinden. Göttingen: Hogrefe 2003:305-309.

-31 Mühle C, Huttner HB, Walter S, Reichel M, Canneva F, Lewczuk P, Gulbins E, Kornhuber J: Characterization of acid sphingomyelinase activity in human cerebrospinal fluid. PLOS ONE 2013;8:e62912. 


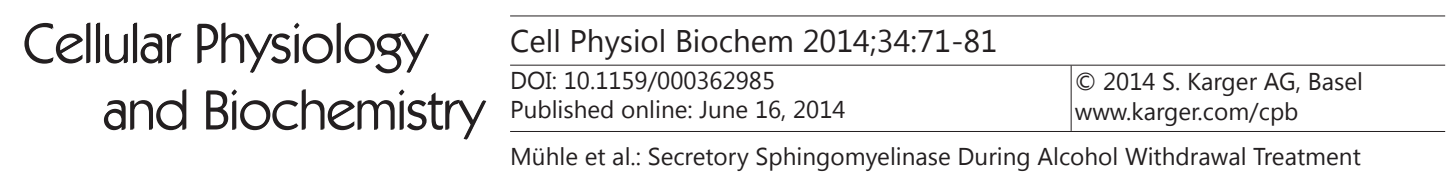

32 Wilsnack RW, Vogeltanz ND, Wilsnack SC, Harris TR, Ahlstrom S, Bondy S, Csemy L, Ferrence R, Ferris J, Fleming J, Graham K, Greenfield T, Guyon L, Haavio-Mannila E, Kellner F, Knibbe R, Kubicka L, Loukomskaia M, Mustonen H, Nadeau L, Narusk A, Neve R, Rahav G, Spak F, Teichman M, Trocki K, Webster I, Weiss S: Gender differences in alcohol consumption and adverse drinking consequences: Cross-cultural patterns. Addiction 2000;95:251-265.

-33 Forquer MR, Hashimoto JG, Roberts ML, Wiren KM: Elevated testosterone in females reveals a robust sex difference in altered androgen levels during chronic alcohol withdrawal. Alcohol 2011;45:161-171.

34 Lee JT, Peng GS, Chen SY, Hsu CH, Lin CC, Cheng CA, Hsu YD, Lin JC: Homocysteine induces cerebral endothelial cell death by activating the acid sphingomyelinase ceramide pathway. Prog Neuropsychopharmacol Biol Psychiatry 2013;45:21-27.

-35 Bleich S, Degner D, Wiltfang J, Maler JM, Niedmann P, Cohrs S, Mangholz A, Porzig J, Sprung R, Rüther E, Kornhuber J: Elevated homocysteine levels in alcohol withdrawal. Alcohol Alcohol 2000;35:351-354.

-36 Marathe S, Schissel SL, Yellin MJ, Beatini N, Mintzer R, Williams KJ, Tabas I: Human vascular endothelial cells are a rich and regulatable source of secretory sphingomyelinase. Implications for early atherogenesis and ceramide-mediated cell signaling. J Biol Chem 1998;273:4081-4088.

-37 Rhein C, Tripal P, Seebahn A, Konrad A, Kramer M, Nagel C, Kemper J, Bode J, Mühle C, Gulbins E, Reichel M, Becker CM, Kornhuber J: Functional implications of novel human acid sphingomyelinase splice variants. PLOS ONE 2012;7:e35467.

-38 Doehner W, Bunck AC, Rauchhaus M, von Haehling S, Brunkhorst FM, Cicoira M, Tschope C, Ponikowski P, Claus RA, Anker SD: Secretory sphingomyelinase is upregulated in chronic heart failure: A second messenger system of immune activation relates to body composition, muscular functional capacity, and peripheral blood flow. Eur Heart J 2007;28:821-828.

-39 Majumdar I, Mastrandrea LD: Serum sphingolipids and inflammatory mediators in adolescents at risk for metabolic syndrome. Endocrine 2012;41:442-449.

-40 Kornhuber J, Medlin A, Bleich S, Jendrossek V, Henkel AW, Wiltfang J, Gulbins E: High activity of acid sphingomyelinase in major depression. J Neural Transm 2005;112:1583-1590.

-41 Kornhuber J, Muehlbacher M, Trapp S, Pechmann S, Friedl A, Reichel M, Mühle C, Terfloth L, Groemer TW, Spitzer GM, Liedl KR, Gulbins E, Tripal P: Identification of novel functional inhibitors of acid sphingomyelinase. PLOS ONE 2011;6:e23852.

42 Kornhuber J, Tripal P, Reichel M, Mühle C, Rhein C, Muehlbacher M, Groemer TW, Gulbins E: Functional inhibitors of acid sphingomyelinase (FIASMAS): A novel pharmacological group of drugs with broad clinical applications. Cell Physiol Biochem 2010;26:9-20.

43 Gulbins E, Palmada M, Reichel M, Lüth A, Böhmer C, Amato D, Müller CP, Tischbirek CH, Groemer TW, Tabatabai G, Becker KA, Tripal P, Staedtler S, Ackermann TF, van Brederode J, Alzheimer C, Weller M, Lang UE, Kleuser B, Grassme H, Kornhuber J: Acid sphingomyelinase-ceramide system mediates effects of antidepressant drugs. Nat Med 2013;19:934-938.

-44 Mielke MM, Bandaru VV, Haughey NJ, Rabins PV, Lyketsos CG, Carlson MC: Serum sphingomyelins and ceramides are early predictors of memory impairment. Neurobiol Aging 2010;31:17-24.

-45 Conigrave KM, Degenhardt LJ, Whitfield JB, Saunders JB, Helander A, Tabakoff B, Group WIS: CDT GGT, and AST as markers of alcohol use: The WHO/ISBRA collaborative project. Alcohol Clin Exp Res 2002;26:332339.

46 Reichel M, Richter-Schmidinger T, Mühle C, Rhein C, Alexopoulos P, Kornhuber J: The common acid sphingomyelinase polymorphism G508R is associated with self-reported allergy. Cell Physiol Biochem 2014;34:82-91. 